Cahiers $d u$ MONDE RUSSE

\section{Cahiers du monde russe}

Russie - Empire russe - Union soviétique et États indépendants

$50 / 2-3 \mid 2009$

L'Europe orientale, 1650-1730. Crises, conflits et renouveau

\title{
Révolutions politiques et identitaires en Ukraine et Biélorussie (1998-2008)Alexandra GOUJON
}

, Paris : Belin, 2009, 268 p.

\section{Anna Colin Lebedev}

\section{(2) OpenEdition}

\section{Journals}

\section{Édition électronique}

URL : https://journals.openedition.org/monderusse/9785

DOI : 10.4000/monderusse. 9785

ISSN : $1777-5388$

\section{Éditeur}

Éditions de l'EHESS

\section{Édition imprimée}

Date de publication : 15 septembre 2009

ISBN : 978-2-7132-2260-3

ISSN : $1252-6576$

\section{Référence électronique}

Anna Colin Lebedev, «Révolutions politiques et identitaires en Ukraine et Biélorussie

(1998-2008)Alexandra GOUJON », Cahiers du monde russe [En ligne], 50/2-3 | 2009, mis en ligne le 14

janvier 2013, consulté le 03 septembre 2022. URL : http://journals.openedition.org/monderusse/9785 ; DOl : https://doi.org/10.4000/monderusse.9785

Ce document a été généré automatiquement le 3 septembre 2022.

Tous droits réservés 


\section{Révolutions politiques et identitaires en Ukraine et Biélorussie (1998-2008)Alexandra GOUJON}

, Paris : Belin, 2009, 268 p.

Anna Colin Lebedev

\section{Alexandra GOUJON, Révolutions politiques et identitaires en Ukraine et Biélorussie (1998-2008), Paris : Belin, 2009, $268 \mathrm{p}$.}

1 L'Ukraine et la Biélorussie, pays voisins issus de la désintégration de l'Union soviétique, ont connu une évolution politique et institutionnelle sensiblement différente. En Ukraine, la "révolution orange», en 2004, a démontré la vitalité de l'opposition politique et sa capacité à structurer une action collective. À l'inverse, en Biélorussie, les mouvements protestataires et notamment la « révolution en jeans» n'ont pas réussi pour l'heure à porter leurs revendications auprès des instances étatiques.

2 L'ouvrage prend, comme point de départ, cette différence et cherche à l'expliquer en analysant les transformations politiques qui ont eu lieu dans chacun des deux États à partir des années 1980. Tout au long du livre, les situations ukrainienne et biélorusse sont mises en parallèle, servant ainsi d'éclairage l'une à l'autre, l'auteur pointant les points communs comme les moments de bifurcation.

3 La présentation suit un ordre faussement chronologique. Si les deux grandes parties correspondent à deux étapes successives - les dernières années de l'Union soviétique et les premières années d'indépendance, le choix de consacrer près de la moitié de l'ouvrage à la période de la perestroïka indique qu'il s'agit pour l'auteur d'un moment clé qui permet en grande partie d'expliquer les évolutions futures des deux pays.

4 La première partie, "Sortir du totalitarisme », couvre les années 1988-1991 et retrace l'évolution politique de l'Ukraine et de la Biélorussie jusqu'à leur accession à 
l'indépendance. Le titre ne rend pas tout à fait compte du point de vue adopté dans cette section qui cherche à montrer l'installation d'un pluralisme politique dans les dernières années de l'URSS, sans interroger la nature totalitaire du régime soviétique tardif.

5 Le chapitre premier décrit les acteurs et les formes de mobilisation politique ayant émergé dans les dernières années soviétiques. Dès les années 1960-1970, un certain nombre de réseaux d'intellectuels - cercles de dissidents, unions de créateurs, groupes informels - ont formé un terreau à partir duquel la contestation s'est structurée par la suite dans des Fronts populaires. Le livre propose une typologie des formes d'action protestataire dans laquelle les nouvelles actions collectives sont opposées à celles qui étaient autorisées et encouragées par le pouvoir soviétique. Il ne s'agit pas tant, pour les acteurs, d'inventer des formats nouveaux que de puiser dans des répertoires d'action collective connus en donnant à l'action une signification et une finalité nouvelles. La manifestation de rue novatrice (de la perestroïka) est ainsi opposée à la manifestation routinière (soviétique); la cérémonie, le meeting et la grève sont également réinterprétés.

Le deuxième chapitre met en évidence le rôle du nationalisme dans les transformations politiques des républiques soviétiques. C'est par opposition à l'idéologie soviétique qui fait de la nationalité un principe de classement et de hiérarchisation des individus, tout en affirmant la supériorité de l'allégeance à la patrie soviétique sur les appartenances nationales, que se structure le discours nationaliste ukrainien et biélorusse. Dès la fin des années 1980, démocratisation et libération nationale sont présentées dans l'idéologie des Fronts populaires comme deux composantes d'un même processus. La renaissance nationale prônée par ces mouvements s'apparente à une réanimation - au sens médical du terme - des nations malades de l'URSS. Le concept de génocide, utilisé pour qualifier à la fois la politique stalinienne et la catastrophe de Černobyl', soutient cet appel. La famille, la morale, la religion, mais surtout la langue nationale sont présentées comme des outils de renaissance ukrainienne et biélorusse.

Les évolutions institutionnelles et politiques qui accompagnent la dislocation de l'URSS, ainsi que l'accès à l'autonomie des républiques d'Ukraine et de Biélorussie, font l'objet du troisième chapitre. Au sein même des institutions soviétiques, la démocratisation entamée pendant la perestroïka permet l'émergence d'une opposition au parti communiste. Le pluralisme politique fait son entrée dans les organes législatifs des républiques. Des partis politiques, souvent issus des Fronts populaires, sont créés. L'ouvrage propose une cartographie de ces partis dans les dernières années de l'Union soviétique en fonction de leur rapport aux idéologies socialiste et nationaliste. Le démantèlement de l'URSS et l'accession à l'indépendance des anciennes républiques permettent la réalisation du projet nationaliste; cependant, elle ne crée pas les conditions d'un renouvellement des élites politiques, puisque les personnes insérées dans les anciens réseaux soviétiques continuent à bénéficier de conditions privilégiées d'accès au pouvoir.

8 La deuxième partie, intitulée "Construire la démocratie ou l'autoritarisme ", analyse l'évolution politique de l'Ukraine et de la Biélorussie à partir de leur accession à l'indépendance. Le quatrième chapitre examine les processus de construction nationale suivis par chacun des deux pays. Si les nouveaux États adoptent une conception civique de la nationalité, les discours politiques valorisent l'ethnie en tant que fondement de la nation. La construction nationale se traduit d'abord par l'élaboration d'une histoire officielle qui met l'accent sur la continuité étatique et ethnique du pays. Toutefois, si 
l'Ukraine s'attache surtout à distinguer son histoire de celle de la Russie, la Biélorussie oscille entre une vision étroitement nationale et une conception panslave de son histoire. La politique linguistique, autre élément clé de la construction nationale, suit aussi des logiques différentes dans les deux pays : si l'Ukraine choisit de promouvoir l'ukrainien en tant qu'unique langue nationale, la Biélorussie fait le choix d'un bilinguisme qui favorise le russe.

9 Le cinquième chapitre porte sur les évolutions - sensiblement différentes - des régimes politiques des deux pays après l'indépendance. L'institution présidentielle, qui joue un rôle clé dans la plupart des pays de l'ex-URSS, repose en Ukraine et en Biélorussie sur un agencement institutionnel similaire, mais donne lieu à des pratiques politiques différentes. Si, en Ukraine, le pouvoir présidentiel est limité par certaines prérogatives du Parlement et par la place du Premier ministre, en Biélorussie s'instaure progressivement un présidentialisme sultanique. De même, si le pluralisme idéologique et le concept de représentation politique sont très forts en Ukraine, le régime biélorusse repose depuis le milieu des années 1990 sur un rejet de cette représentation. L'auteur compare le rôle des parlements, la place des partis politiques et la structuration de l'opposition pour pointer les différences entre les deux régimes.

10 Le dernier chapitre, consacré à la participation politique et à l'action collective, tente de répondre à la question posée en début d'ouvrage quant à l'inégal succès de la protestation collective dans les deux pays. Reprenant la typologie de l'action collective élaborée dans le premier chapitre, l'auteur montre comment la manifestation «novatrice » a été intégrée dans les pratiques politiques courantes en Ukraine, alors qu'elle a été marginalisée au profit de la manifestation « routinière » en Biélorussie. Le succès de la révolution orange, tout comme l'échec de la révolution en jeans, s'explique en grande partie, selon l'auteur, par le régime politique, et notamment par son acceptation du pluralisme qui permet à une opposition de se structurer et de se faire entendre. Le pluralisme politique renvoie à son tour à un pluralisme social: «La démocratisation en Ukraine est ainsi à la fois fondée sur un pluralisme culturel, idéologique, régional, qui est entretenu par et à travers une construction nationale respectueuse du pluralisme politique. Quant à l'autoritarisme en Biélorussie, il n'est pas tant le produit d'une faiblesse de l'identité nationale que la manifestation de sa possible homogénéisation spatiale et sociale » (p. 231).

11 L'ouvrage d'Alexandra Goujon offre ainsi une présentation complète et précise de l'évolution institutionnelle et politique de l'Ukraine et de la Biélorussie à partir des dernières années de l'URSS. Le choix d'une comparaison entre deux pays frontaliers, culturellement proches, porteurs d'une histoire soviétique commune et connaissant pourtant une évolution politique différente, est particulièrement pertinent. La comparaison permet de mesurer le poids du passé soviétique dans la nature des régimes politiques et les répertoires d'action choisis, mais aussi de nuancer une vision déterministe de l'évolution des États postsoviétiques. L'une des idées fortes du livre, que l'on aimerait voir davantage développée, est le lien entre société hétérogène et pluralisme politique du côté ukrainien, homogénéité et autoritarisme du côté biélorusse. L'ouvrage, qui se situe plutôt dans le champ de l'analyse institutionnelle et politique, appelle son pendant sociologique, c'est-à-dire une analyse plus approfondie de la diversité sociale ukrainienne et de l'hétérogénéité biélorusse homogénéisée par le pouvoir. 
12 Un point de vue lié à une discipline suppose toujours des angles morts. Bien que les rouages de la vie politique soient analysés avec une grande précision, les sociétés ukrainienne et biélorusse sont peu présentes dans ce livre. Or, dans des pays où l'on observe souvent un désintérêt des citoyens pour la vie politique et un manque de confiance dans les institutions, une analyse des acteurs politiques peut-elle suffire à expliquer pourquoi des citoyens descendent ou non dans les rues pour protester? 